\title{
HIV BIO-BEHAVIOURAL SURVEY AMONG MEN WHO HAVE SEX With MEN in Barcelona, Bratislava, BuCharest, Ljubljana, Prague and Verona, 2008-2009
}

\author{
M Mirandola (m.mirandola@crrps.org) ${ }^{1}$, C Folch Toda², I Krampac ${ }^{3}$, I Nita ${ }^{4}$, D Stanekova ${ }^{5}$, D Stehlikova ${ }^{6}$, I Toskin7, L Gios ${ }^{1}$, \\ J P Foschia ${ }^{1}$, M Breveglieri ${ }^{1}$, M Furegato ${ }^{1}$, E Castellani ${ }^{1}$, M G Bonavina ${ }^{8}$, the SIALON network ${ }^{9}$ \\ 1. Regional Centre for Health Promotion, ULSS 20 - Veneto Region, Verona, Italy \\ 2. Centre for Epidemiological Studies on HIV/AIDS in Catalonia (CEESCAT), Hospital Universitari Germans Trias i Pujol, \\ Barcelona, Spain \\ 3. Regional Public Health and Health Promotion Centre, Maribor, Slovenia \\ 4. ACCEPT Association, Bucharest, Romania \\ 5. National Reference Centre for HIV/AIDS - Slovak Medical University, Bratislava, Slovakia \\ 6. National Institute of Public Health, Prague, Czech Republic \\ 7. Monitoring and Evaluation Division, Joint United Nations Programme on HIV/AIDS (UNAIDS), Geneva, Switzerland \\ 8. Azienda ULSS 20 - Veneto Region, Verona, Italy \\ 9. Members of the SIALON network are listed at the end of the article
}

This article was published on 9 December 2009.

Citation style for this article: Mirandola M, Folch Toda C, Krampac I, Nita I, Stanekova D, Stehlikova D, Toskin I, Gios L, Foschia JP, Breveglieri M, Furegato M, Castellani E, Bonavina MG, the SIALON network. HIV bio-behavioural survey among men who have sex with men in Barcelona, Bratislava, Bucharest, Ljubljana, Prague and Verona, 20082009. Euro Surveill. 2009;14(48):pii=19427. Available online: http://www.eurosurveillance.org/ViewArticle.aspx?ArticleId=19427

Data from 23 European countries show that the annual number of HIV diagnoses in men who have sex with men (MSM) increased by $86 \%$ between 2000 and 2006 . This paper reports the main preliminary results of a bio-behavioural survey in MSM with a specific focus on HIV prevalence and use of United Nations General Assembly Special Session (UNGASS) indicators in six cities in Southern and Eastern Europe. Time-location sampling (TLS) was used. A total number of 2,356 questionnaires and 2,241 oral fluid samples were collected (invalid samples $4.1 \%$ ). The data show different socio-demographic patterns across countries regarding age, level of education, living conditions, living area and selfidentity. Southern European cities had the highest percentage of people who had tested for HIV and collected the result. More than $50 \%$ of respondents in the sample from Barcelona reported having used a condom last time they had anal sex (57.2\%), whilst in all other cities this proportion was below $50 \%$. The cities with the highest HIV prevalence in MSM were Barcelona (17.0\%) and Verona (11.8\%) whilst lower percentages were reported in Bratislava (6.1\%), Bucharest (4.6\%), Ljubljana (5.1\%) and Prague (2.6\%). The low prevalence in Eastern European cities is encouraging. However, with the level of high-risk sexual behaviour documented and the lower frequency of HIV test seeking behaviour, there is a clear risk of an increase in HIV transmission.

\section{Introduction}

HIV infection remains an important public health issue in Europe, with evidence of continuing transmission in many countries. Accounting for almost one third $(7,693)$ of all reported newly diagnosed HIV infections reported in 2006 in European Union (EU) and European Free Trade Association (EFTA) countries, Men who have sex with men (MSM) continue to represent a population at high risk of HIV infection [1,2]. Data from 23 European countries show that the annual number of HIV diagnoses in MSM increased by $86 \%$ between 2000 and 2006 [2]. The results of some seroprevalence studies in gay community settings or healthcare services suggest levels of HIV prevalence between 10 and 20\% among MSM, and available data suggest a possible hidden HIV epidemic in this population group [2,3].

In addition to the spread of HIV, an increase of high risk sexual behaviour among MSM is reported throughout Europe $[1,2]$. In this context, HIV testing has become a key surveillance activity for monitoring the HIV epidemic especially in hard-to-reach MSM. Since the introduction of highly active antiretroviral therapy (HAART), AIDS has become less indicative of the underlying trends in HIV infection. Another important factor linked to risk behaviour and risk of HIV transmission is the use of alcohol and other psychoactive drugs. According to the literature, alcohol and illicit drug consumption significantly increase the odds of having sex and have a significant positive association with the sexual risk.

Several studies, both in Europe and the United States (US), show a high percentage of MSM who use alcohol and drugs before and during sex and an association between these substances and sexual risk behaviour [4-6]. Additionally other studies suggest that even intermittent, recreational use of these drugs before or during sexual intercourse may lead to high-risk sexual behaviour (e.g. unprotected anal intercourse, UAI), especially with casual partners $[7,8]$. Recent studies of the sexual risk behaviour of MSM have also described a range of changes in sexual risk-taking behaviour in MSM in recent years, with an increased number of partners in some countries. The number of partners proved to be one of the strongest predictors of unsafe sex; according to the literature, the probability of having had unsafe sex ranged from $17 \%$ in men with one partner to $58 \%$ in men with more than 20 partners [9-11].

Despite these findings, few studies targeted MSM using outreach methods collecting behavioural and biological data in line with 
Second Generation Surveillance System (SGSS) criteria [12,13] and United Nations General Assembly Special Session (UNGASS) indicators $[3,14]$. The Second Generation Surveillance System combines monitoring of newly diagnosed HIV cases and indicators of sexual behaviour among persons in groups at highest risk for infection.

Previous community-based surveys targeting MSM in Scotland, which included both questionnaires and anonymous oral fluid testing for HIV, found high levels of HIV prevalence and risk behaviour and low uptake of HIV testing [15]. The advantage of oral fluid collection for testing of infection is evident as it is a minimally invasive method for serological monitoring which is easy and safe. It has proven to be acceptable for various target audiences and it does not require trained staff $[16,17]$. Therefore, the use of oral fluid as a means for biological testing is of crucial importance in order to gather valid and reliable information about the spread of HIV among hard to reach populations such as MSM.

Taking these factors into account, the 2008-2009 study was designed to gather reliable information on HIV prevalence among MSM in Southern and Eastern Europe.

This paper reports preliminary results of the SIALON project Capacity building in HIV/Syphilis prevalence estimation using noninvasive methods among MSM in Southern and Eastern Europe, with a specific focus on HIV prevalence and use of UNGASS indicators.

\section{Methods}

\section{Study design}

The study was a descriptive multi-centre biological and behavioural cross-sectional survey and was carried out in seven cities of Southern and Eastern European countries: Athens, Greece; Barcelona, Spain; Bratislava, Slovakia; Bucharest, Romania; Ljubljana, Slovenia; Prague, Czech Republic; Verona, Italy. In this report Bratislava, Bucharest, Ljubljana and Prague were defined as Eastern European cities. The survey was designed to obtain an estimate of the prevalence of HIV in the study population, MSM attending gay venues.

Ethics Committee approval was obtained in each participating country and an informed consent form was collected for each respondent. The questionnaires and the oral fluid samples were collected anonymously. In order to make the test result available to interested individuals, a barcode was used to link the respondents to the test result via a card with the same barcode given to the respondents when oral fluid was collected. To comply with all ethical and legal aspects and minimise the risks of diagnostic mistakes, respondents interested in getting their test results were informed that the test result was not meant to be diagnostic and for this reason they should be tested again in line with international/

\section{F I G U R E 1}

Age distribution of participants of an HIV bio-behavioural survey among men who have sex with men in Barcelona, Bratislava, Bucharest, Ljubljana, Prague and Verona, 2008-2009

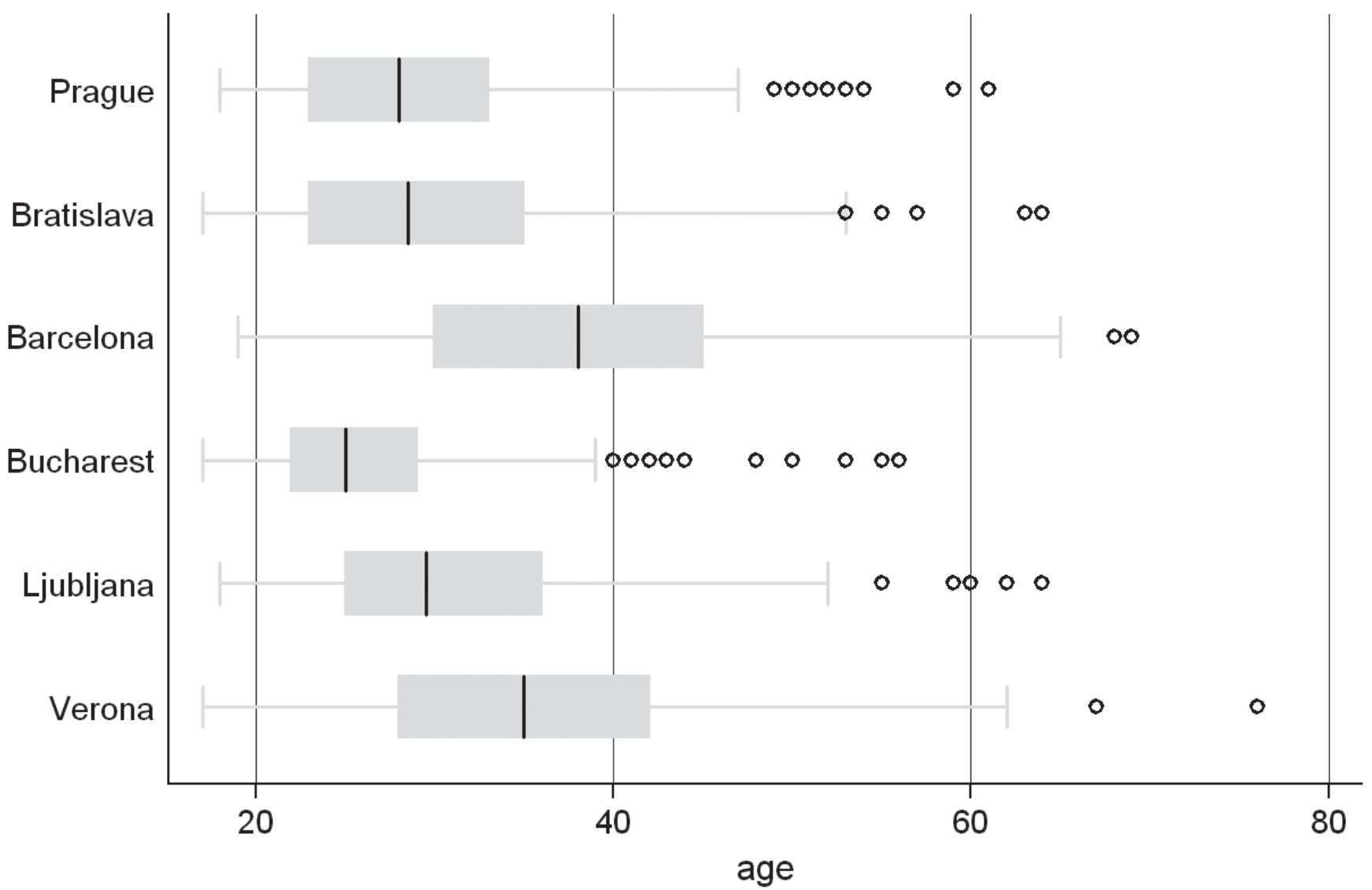


national guidelines. In case of a confirmed positive HIV test, the person was directed to the infectious disease department for further Percentage of men who have sex with men (MSM) who selfidentified themselves as gay/homosexual, bisexual and heterosexual; HIV bio-behavioural survey among men who have sex with men in Barcelona, Bratislava, Bucharest, Ljubljana, Prague and Verona, 2008-2009

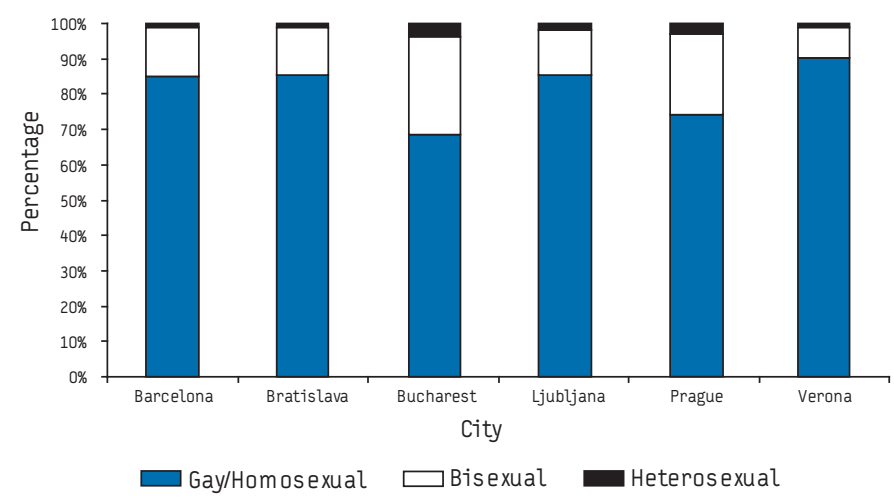
checks of their clinical situation and start antiretroviral treatment if needed.

\section{Study population}

Participants were recruited according to the following four inclusion criteria: having had sex (any kind of sex: oral and anal, penetrative or not) at least once with another man during the last 12 months before the study; having signed a written informed consent form; having agreed to answer the study questionnaire; having accepted to donate an oral fluid sample. Three exclusion criteria were adopted: age below 18 years; currently active injecting drug use (IDU) and having already participated in the study.

\section{Sampling}

Time-location (or time-space) sampling (TLS) was used to recruit representative samples of men visiting the gay scene in each city. The method used was consistent with the approach adopted in previous studies [15-21]. In the TLS, spaces (or locations) are venues attended by the target population; times refer to specific days and time periods when the target population congregates in each space. This method allows a sample with known properties to be identified and enables statistical inferences to be made to the larger population of venue visitors. Formative research was conducted in each collection location in order to identify the list of potential TLS units, the attendance time frame, opening days and hours of each venue. Bars, discos, saunas, cruising venues, sex-shops, sex-clubs were identified in all cities. All venues were mapped and visited when information on attendance patterns was not sufficient to prepare a TLS units list. The spaces and their associated days were divided into standardised time segments (four-hour periods). Subjects were enrolled over the entire TLS unit time period. Information on the number of refusals per TLS unit was collected. Furthermore, settings or special gay events that did not occur frequently were identified. A "special events" category was created and included in the sampling list because such occasions may attract members of the target population. The list of TLS units obtained with this process for each collection site included the primary sampling units (PSU). PSU were randomly selected from complete list of eligible TLS list in each city. The sample size estimation for a prevalence study was calculated on

\section{TA B L E 2}

Percentage of respondents who consistently used a condom in the last six months with steady and casual partners, separately for anal and oral sex; HIV bio-behavioural survey among men who have sex with men in Barcelona, Bratislava, Bucharest, Ljubljana, Prague and Verona, 2008-2009

\begin{tabular}{|c|c|c|c|c|c|c|c|c|}
\hline & $\begin{array}{l}\text { Condom use during anal } \\
\text { sex with steady partner }\end{array}$ & & $\begin{array}{l}\text { Condom use during anal } \\
\text { sex with casual partner }\end{array}$ & & $\begin{array}{l}\text { Condom use during oral } \\
\text { sex with steady partner }\end{array}$ & & $\begin{array}{l}\text { Condom use during oral } \\
\text { sex with casual partner }\end{array}$ & \\
\hline \multirow{2}{*}{ Total } & \multicolumn{2}{|l|}{$N=1,402$} & \multicolumn{2}{|l|}{$N=1,383$} & \multicolumn{2}{|l|}{$N=1,517$} & \multicolumn{2}{|l|}{$N=1,567$} \\
\hline & $\%$ & $95 \% \mathrm{CI}^{\mathrm{a}}$ & $\%$ & $95 \% \mathrm{CI}$ & $\%$ & $95 \% \mathrm{CI}$ & $\%$ & $95 \% \mathrm{CI}$ \\
\hline Barcelona & 43,0 & $\pm 7,0$ & 65,4 & $\pm 5,5$ & 9,3 & $\pm 4,0$ & 13,1 & $\pm 3,8$ \\
\hline Bratislava & 19,9 & $\pm 5,2$ & 41,7 & $\pm 6,9$ & 1,2 & $\pm 1,4$ & 6,2 & $\pm 3,1$ \\
\hline Bucharest & 43,1 & $\pm 6,0$ & 51,8 & $\pm 6,2$ & 8,6 & $\pm 3,3$ & 15,1 & $\pm 4,3$ \\
\hline Ljubljana & 36,6 & $\pm 6,1$ & 58,8 & $\pm 7,2$ & 5,5 & $\pm 2,7$ & 10,4 & $\pm 4,0$ \\
\hline Prague & 25,6 & $\pm 5,4$ & 36,3 & $\pm 6,8$ & 5,8 & $\pm 2,8$ & 9,6 & $\pm 3,7$ \\
\hline Verona & 40,2 & $\pm 6,4$ & 56,1 & $\pm 5,9$ & 5,8 & $\pm 3,0$ & 8,1 & $\pm 3,0$ \\
\hline
\end{tabular}

${ }^{a}$ Confidence interval 
the basis of previous prevalence estimation studies when available [22]. A total of 2,800 persons (400 per city) were included in the planned survey.

\section{Data collection}

\section{Questionnaire}

A self-administered pen-and-paper questionnaire was used to obtain information on the social/cultural/environmental context of respondents, access and barriers to voluntary counseling and testing (VCT), behavioural data on sex practices, risk-reducing strategies, condom use), STI history, self-reported/perceived serostatus and type of partner. A steady partner was defined in the questionnaire as "a person who you are committed to and have sex with, not meaning that, you are exclusively monogamous"; casual partner as "person you have sex with, occasionally without a steady partnership". In addition, UNGASS indicators were taken into account when designing the questionnaire $[3,14]$. The preliminary version of the questionnaire was piloted among MSM attending gay venues to check on the time needed to complete it and to ensure the questions were not ambiguous or confusing. The English version of the questionnaire was translated into the languages of the participating countries and then translated back into English.

A questionnaire manual and a training module were developed in order to guarantee uniform data collection. Specific training of data collectors was held in each country in a one day session by a data collection coordinator. The same coordinator was in charge of monitoring the local data collection and coaching the data collectors during the task. An ongoing evaluation process was organised through regular meetings with data collectors.

\section{Oral Fluid sampling and testing}

To collect oral fluids, Oracol oral fluid collection kits (Malvern Medical Developments, Worcester, UK) were used. The main advantages for replacing serum with oral fluid were easy access and non-invasive collection. After collection, oral fluid samples were kept refrigerated and sent to the national reference laboratory for HIVIAIDS in the respective countries no more than 72 hours after collection.

\section{Laboratory testing}

The oral fluid samples were sent for the analysis by each national reference laboratory to the Teaching Hospital-University of Verona, Immunology Unit, Verona, Italy. EIA testing GENSCREEN HIV 1/2 version 2, BIO-RAD on oral fluid sample was performed according to the manufacture's instructions [23]. All positive samples were confirmed with a Western Blot test. As quality control, for each oral fluid sample, a total IgG antibodies ELISA test was performed in order to assess the sample suitability for testing. Samples below 3.5 titre (cut-off) were excluded from the study as invalid. A validation study of Bio-Rad OF testing comparing serological testing involving 37 HIV positive patients and 35 controls per country was carried out according to commission decision of 7 May 2002 on common technical specifications for in vitro medical devices. Validation, with 504 paired oral fluid and serum samples, yielded a 99\% sensibility and $99 \%$ specificity, which gives PPV of $94.6 \%$ and NPV of $99.8 \%$ for a prevalence of $15 \%$. For a prevalence of $5 \%$ these figures are $83.9 \%$ and $99.9 \%$ respectively.

\section{Enrolment}

According to the data collection calendar, trained field workers from gay associations distributed anonymous self-complete questionnaires and Oracol oral fluid collection kits. Both selfcomplete questionnaire (behavioural data) and oral fluid samples (biological data) were collected for each subject. A barcode was used to link behavioural and biological information. The enrolment period varied between cities. The data collection calendar varied from two months in Barcelona and Verona to nine months Bratislava and Bucharest.

T A B L E 3

Number of steady and casual partners in the last six months; HIV bio-behavioural survey among men who have sex with men in Barcelona, Bratislava, Bucharest, Ljubljana, Prague and Verona, 2008-2009

\begin{tabular}{|c|c|c|c|c|c|c|c|}
\hline & & Barcelona & Bratislava & Bucharest & Ljubljana & Prague & Verona \\
\hline \multicolumn{2}{|l|}{ Steady partner } & $n=161$ & $n=238$ & $n=256$ & $n=258$ & $n=242$ & $n=221$ \\
\hline & Mean & 1,6 & 2,0 & 3,3 & 2,1 & 2,7 & 2,6 \\
\hline & $\mathrm{SD}^{\mathrm{a}}$ & 1,7 & 2,2 & 4,5 & 2,5 & 3,6 & 3,6 \\
\hline & P25 & 1 & 1 & 1 & 1 & 1 & 1 \\
\hline & Median & 1 & 1 & 2 & 1 & 1 & 1 \\
\hline & $P 75^{\mathrm{b}}$ & 1 & 2 & 3 & 2 & 3 & 3 \\
\hline & $I Q R^{\circ}$ & 0 & 1 & 2 & 1 & 2 & 2 \\
\hline \multicolumn{2}{|l|}{ Casual partner } & $n=269$ & $n=232$ & $n=249$ & $n=219$ & $n=205$ & $n=293$ \\
\hline & Mean & 16,3 & 6,1 & 7,1 & 5,7 & 7,5 & 12,0 \\
\hline & SD & 20,5 & 8,6 & 9,4 & 8,9 & 10,5 & 16,1 \\
\hline & P25 & 4 & 2 & 2 & 2 & 2 & 3 \\
\hline & Median & 10 & 3 & 3 & 3 & 4 & 6 \\
\hline & P75 & 20 & 6 & 7 & 6 & 10 & 12 \\
\hline & IQR & 16 & 4 & 5 & 4 & 8 & 9 \\
\hline
\end{tabular}




\section{Statistical Analysis}

As the focus of the study was descriptive, mean, median, standard deviation, quartiles and inter-quartiles were used and proportions with $95 \%$ confidence intervals $(\mathrm{Cl})$ were calculated for all variables and indicators. STATA 11 survey commands suite was used.

\section{Results}

A total of 2,362 questionnaires and 2,365 oral fluid samples were collected in six of the seven cities. The total number of valid questionnaires was 2,356 (99.7\%) whilst for the valid oral fluid samples it was 2,241 (94.8\%) The proportion of valid oral fluid samples over valid questionnaires by city was respectively: Barcelona 97\% (388/400), Bratislava 98\% (342/349), Bucharest 86.7\% (345/398), Ljubljana 97.7\% (389/398), Prague 95.1\% (387/407), Verona 96.5\% (390/404). Athens, Greece was not included in the analysis as data was not available at the time of this paper.

The time of questionnaire completion ranged from 10 to 20 minutes. The time length was related to age and the type of venues.

\section{Study population}

The median age and 1st and 3rd quartile by city are presented in Figure 1. Respondents in Barcelona and Verona had a similar age distribution and were older, (38 and 35 years respectively) than those in the Eastern European cities; in Bucharest the median age of respondents was 25 years, followed by Prague and Bratislava (28 years). In Ljubljana the median age was 29.5 years.

As regards education level, MSM in Barcelona had the highest proportion of university degrees (53.6\%) and MSM in Prague the lowest (27.4\%).

In most of the cities the largest group of respondents lived alone (living conditions): $41.8 \%$ in Prague, $40.8 \%$ in Verona, $37.4 \%$ in Barcelona and $36.9 \%$ in Ljubljana. Exceptions were Bucharest

\section{F I G U R E 3}

Percentage of respondents reporting use of alcohol, poppers, ecstacy, Viagra, cannabis, cocaine and amphetamine before or during sex over the last six months; HIV bio-behavioural survey among men who have sex with men in Barcelona, Bratislava, Bucharest, Ljubljana, Prague and Verona, 2008-2009

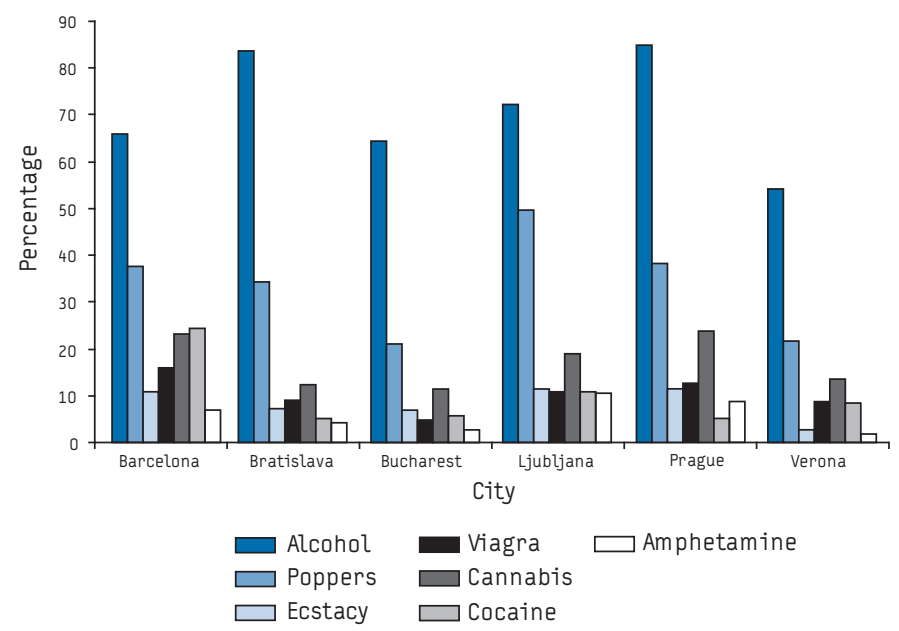

and Bratislava, where respondents lived mostly with their parents (34.1\% and $30.2 \%$ respectively). In Verona, a high proportion of MSM lived with their parents (30.1\%), although a larger number lived alone. Barcelona had the highest proportion of respondents living with friends (22.9\%), while the highest proportion living with male partners were in Prague (27.5\%) and Bratislava $(27.6 \%)$ followed by Ljubljana (23.4\%). The percentage of respondents living with a heterosexual family (female partner and/or offspring) was generally lower than $8 \%$, ranging from $4.9 \%$ in Bratislava to $7.7 \%$ in Verona.

In almost all cities the majority of respondents lived in areas with more than 100,000 inhabitants, ranging from $61.4 \%$ in Bratislava to $82.9 \%$ in Bucharest, with the only exception of Verona, where the majority of respondents lived in a village with less than 10,000 inhabitants (32.7\%) or in a small town with 10,000 to 100,000 inhabitants (25.3\%).

The data for self-identified sexual orientation are presented in Figure 2. More than $80 \%$ of the respondents self-identified themselves as homosexual in Barcelona, Bratislava, Ljubljana and Verona. The highest proportion of bisexuals and heterosexuals was found in Bucharest (27.6\% and 3.9\% respectively) and in Prague (22.6\% and $3 \%$ respectively), while the lowest was in Verona $(8.7 \%$ and $1 \%$ respectively). In the remaining cities the percentage of bisexuals was similar, ranging from $12.7 \%$ in Ljubljana to $14.4 \%$ in Bratislava.

\section{HIV prevalence and testing}

Table 1 presents the prevalence of HIV infection among MSM based on the oral fluid tests. The cities with the highest HIV prevalence were Barcelona (17.0\%) and Verona (11.8\%); lower percentages were reported in Bratislava (6.1\%), Bucharest (4.6\%) and Ljubljana (5.1\%). Prague had the lowest HIV prevalence $(2.6 \%)$.

In order to monitor HIV testing uptake, UNGASS indicator number eight was used. This indicator comprises the percentage of MSM tested for HIV over the last 12 months who also collected the result. Table 1 presents the UNGASS 8 estimate by city.

Southern European cities had the highest percentage of tested people who received their HIV test result $(56.2 \%$ in Barcelona and $53 \%$ in Verona), while the Eastern European cities had the lowest percentages, ranging from $32.1 \%$ in Bratislava to $43.2 \%$ in Bucharest. Among the respondents who had taken an HIV test over the last 12 months, the percentage of subjects who decided to collect the test result was over $90 \%$ in Verona and Barcelona (93.9\% and $92.6 \%$ respectively) while in Prague it was $85.9 \%$, in Bratislava $83.6 \%$ and $78.3 \%$ in Ljubljana. The lowest percentage was in Bucharest (74.9\%).

\section{Condom use}

In order to estimate the risk reduction strategies of MSM during the most at-risk sexual behaviour, namely anal sex, UNGASS indicator number 19 was used. This indicator describes the percentage of men reporting the use of a condom during their last anal sex episode with a male partner in the previous six months. Table 1 presents the UNGASS 19 estimate by city. More than $50 \%$ of respondents in the sample from Barcelona reported using a condom the last time they had anal sex (57.2\%), while in all other cities this percentage was below $50 \%$. In three cities percentages were above 40\% (Verona: 45.6\%, Ljubljana: 43\%, Bucharest: 
42.7\%), while percentages were lowest in Prague (29.8 \%) and Bratislava (30,8\%).

\section{Consistent condom use}

Respondents were asked to indicate the frequency of protected anal and oral sex both with a steady and a casual partner over the last six months. Consistent condom use is defined as the use of a condom (often or always) in the last six months during sexual intercourse, both receptive and insertive. Sexual behaviour was analysed separately for anal sex and oral sex. Table 2 shows the percentage of consistent condom use by type of partner and city. As far as anal sex is concerned, condom use with a steady partner was declared by $43.1 \%$ of respondents in Bucharest and $43 \%$ in Barcelona, followed by Verona (40.2\%) and Ljubljana (36.6\%), while the lowest condom use was reported in Prague $(25.6 \%)$ and Bratislava (19.9\%). Condom use with a casual partner for anal sex is in general more likely to be reported than with a steady partner. The highest level of consistent condom use with a casual partner was reported by MSM in Barcelona (65.4\%), whilst the lowest was in Prague (36.3\%). In Ljubljana consistent condom use was reported by $58.8 \%$ of respondents who had anal sex with a casual partner, followed by MSM in Verona (56.1\%), in Bucharest (51.8\%) and in Bratislava (41.7\%).

As far as consistent condom use in oral sex over the last six months is concerned, the level was dramatically lower compared with anal sex. In Barcelona, 9.3\% of respondents reported condom use with a steady partner followed by Bucharest ( $8.6 \%)$; a virtually identical level was reported in Prague (5.8\%), Verona (5.8\%) and Ljubljana (5.5\%). The lowest level of condom use in oral sex with a steady partner was reported in Bratislava (1.2\%). For casual partners, consistent condom use in oral sex was reported by $15.1 \%$ of respondents in Bucharest, 13.1\% in Barcelona and $10.4 \%$ in Ljubljana, whilst the lowest proportion was found in Verona (9.1\%) and Bratislava (6.2\%).

\section{Number of partners}

The highest average number of steady partners over the last six months reported by respondents was in Bucharest (3.3) and the lowest in Barcelona (1.6), although the medians show a more similar distribution between the cities, with two partners in Bucharest and one partner elsewhere (Table 2). For casual partners, the highest mean and median were reported in Barcelona (mean 16.3, median 10), followed by Verona (mean 12, median 6) and Eastern European cities (mean ranging from 5.7 to 7.5 and median from 3 to 4 ).

\section{Psychoactive and recreational drug use over the last six months}

Substance use before or during sex over the last six months is demonstrated in Figure 4. As expected, alcohol proved the substance with the highest rate of consumption in each city. The highest percentages were reported in Prague and Bratislava (85\% and $83.7 \%$ respectively), whilst the lowest level was in Verona (54.2\%).Poppers are one of the most popular substances in the gay scene and some authors refer to it as a gay drug [4]. The highest rate of poppers use was found in Ljubljana (49.8\%) whilst lower use was reported in Prague, Bucharest and Barcelona $38.1 \%$, $34.2 \%$ and $37.6 \%$ respectively). The lowest percentages were reported in Verona (21.6\%) and Bucharest (21\%). For ecstacy, the percentages of consumption were $11.4 \%$ in Prague, $11.3 \%$ in Ljubljana and $10.9 \%$ in Barcelona. Sixteen per cent MSM in Barcelona reported use of viagra, $12.7 \%$ in Prague. Lower levels of consumption were reported in Bucharest (4.7\%), Verona (8.6\%) and Bratislava (9.1\%). High levels of Cannabis use were reported in Prague, Barcelona and Ljubljana (23.8\%, 23.2\% and $19.1 \%$ respectively), while lower rates were reported in Verona (13.4\%), Bratislava (12.5\%) and Bucharest (11.5\%). A high consumption of Cocaine was found in Barcelona (24.5\%). Similar levels of consumption were found in the MSM samples in Prague $(5.1 \%)$, Bratislava (5.2\%), Bucharest (5.8\%) and Verona (8.3\%). The rate of amphetamine use ranged between $1.9 \%$ in Verona and $10.4 \%$ in Ljubljana.

\section{Discussion and conclusion}

Valid and comparable data on HIV prevalence related to HIV risk behaviour in a hard to reach population are lacking. However, such information is important for development of effective prevention strategies. In order to respond to this limitation, the SIALON project, used three key elements of behavioural and prevalence studies among MSM for improving data comparability: time and location sampling (TLS) method, oral fluid testing in outreach settings and UNGASS indicators.

The use of TLS as a sampling method proved to be feasible and efficient in cities with highly developed gay scenes as well as in cities with less developed scenes. As previous studies among MSM have shown, TLS increases the possibility of involving a variety of participants, producing more valid results [15]. A generalisation of the estimates obtained with this method to the wider population of MSM attending sampled venues is also possible. TLS can be adopted on a larger scale and the method is easily applicable in cities with a considerable number of eligible gay venues. It is more difficult to implement in cities where the gay community is poorly organised and where there are few specific and easily accessible venues. Few venues means that the venues available are overvisited by data collectors, thus reducing the acceptance of the data collection process both to owners of venues and attendees. This aspect may impact the representativeness of the MSM sample of the whole MSM population and therefore reduce the efficiency of TLS. In addition, the TLS method does not take into account other ways of recruiting, such as the internet, gay magazines, chat room etc. However, as one of the main focuses of our study was to estimate HIV prevalence through the collection of biological samples, these alternative sources of recruitment were excluded.

For surveillance and epidemiological purposes, oral fluid testing has clear advantages over venopuncture in community settings and is an alternative screening tool in outreach settings among high-risk populations. Oral fluid testing simplifies the diagnostic process in specific populations in which drawing blood is difficult and dangerous. As previously demonstrated in other studies, the number of oral fluid collections in all sites confirmed the general acceptability of the study by MSM in outreach settings $[16,24]$. In our study, an info-pack containing a condom, a lubricant and information about STD prevention and screening centres available in the area was given to respondents in order to facilitate the enrolment and to promote safer sex and testing practice, during the data collection.

The introduction of UNGASS indicators is a key measure for the basic monitoring of HIV across countries with comparable indicators. According to UNAIDS, data from multiple countries collected following UNGASS procedures can supply critical information and comparative insights at the regional and the global level. Data can provide a snapshot as well as trend analysis of the epidemiology of HIV over time [3,14]. As far as our study results are concerned, the data shows a variety of socio-demographic patterns among the cities in relation to age, education, living conditions, 
living area and self-identity. At this stage, the results presented in this paper are mainly descriptive and this is of course a limitation of the study. A multilevel, multivariate analysis will be carried out in the future to better understand the relationship between HIV prevalence and other factors.

HIV testing (UNGASS 8) is an important indicator of the healthcare system's ability to reach MSM and to efficiently provide access to screening. Verona and Barcelona had the highest percentages of tested people who collected the HIV test result. This finding reflects not only the lower access to HIV testing in Eastern European cities, but also how VCT is organised and might be an indicator of health practitioners' attitudes on health seeking behaviour. The high percentage of MSM seeking the test result in Verona and Barcelona seems to indicate better VCT practice. Differences in stigma, health service organisation and country specific barriers to accessing VCT could explain the gap between Southern and Eastern European cities. Data on condom use (UNGASS 19) seem to suggest that protected sex is more frequently performed in Southern European cities, particularly in Barcelona. Interestingly, HIV prevalence was highest in Barcelona and Verona, where condom use was also highest. This may reflect a different distribution of HIV prevention programmes. In more detail, data about the type of sexual partner, sexual intercourse and condom use confirm the findings of other studies. It is evident that the differentiation between steady and casual partners leads to different distribution of sexual practice. According to the literature, in some countries the number of sexual partners seems to have increased in recent years $[25,26]$. This may be a good proxy variable for unsafe sex [9]. As expected, throughout our sample, the number of casual partners was higher than the number of steady partners, although in some countries this difference was far more marked than in others. When considering different sexual behaviour (anal and oral sex) related to different types of sexual partners in the last six months, similar patterns occur. As already well-established by other studies, the rates of condom use differ in relation to the kind of partners and sexual practices: protected sex with casual partners is more frequent than with a steady partner, and protected anal sex is more frequent than protected oral sex [27].

As far as substance use is concerned, alcohol consumption is broadly reported in all cities, with the highest levels in Prague and Bratislava. These findings may be related to the younger age of respondents but also to some contextual variables in Eastern European cities. According to the international literature, poppers seems to be the main substance used in the MSM population [4]. Our findings confirm the high levels of poppers consumption, especially in Ljubljana, Prague and Barcelona. As far as the use of other illicit drugs is concerned, cannabis is widely used, but there are large differences between cities. With regard to cocaine consumption, in Barcelona, $24.5 \%$ of respondents reported they had used it sometimes or often during the last six months, before or during sex. Even though an overestimation of substance use could not be excluded, it seems that drug use was frequent in our sample. Taking into account the fact that even an intermittent recreational use of drugs before or during sexual intercourse may lead to highrisk sexual behaviour, the data seem to be relevant and suggest a need for prevention programmes targeting MSM, with particular attention to alcohol, poppers and drug use.

Despite possible biases in this prevalence study in some countries, the data emerging from the survey show varying levels of HIV infection among the recruited MSM. The highest prevalence was in Barcelona and Verona, while the prevalence in Eastern
European countries was lower. Previous studies carried out in some of the cities participating in this study, came to different prevalence estimates. In Barcelona HIV prevalence found in a last previous study carried out in MSM venues (using a convenience sample) was slightly higher than the prevalence found in this study [28]. The lower figures found in Ljubjana and Bratislava in previous studies, may be partly related to a different sampling method and lower number of samples collected $[29,30]$.

The low prevalence found in the four Eastern European cities is encouraging. However, with the level of unprotected anal sex in some of these cities, even with casual partners, and a generally low frequency of HIV test- seeking behaviour, the potential for further HIV transmission in Eastern European cities is evident.

Members of the SIALON network:

Ivo Procházka, Czech AIDS Help Society (ČSAP), Czech Republic; Alex Horký, Czech Youth Queer Organization,Czech Republic; Zeno Menegazzi, Arcigay Italia; Alin Robert Zoltan, ACCEPT Romania, Romania; Jaro Gyurik, Z druženie Prevencie AIDS (ZPA), Slovakia; Miran Šolinc, ŠKUC Magnus, Slovenia; Rafa Muñoz, Stop Sida,Spain.

Financial support:

The Capacity building in HIV/Syphilis prevalence estimation using non-invasive methods among MSM in Southern and Eastern Europe - SIALON project was funded by the European Commission under the European Commission Public Health Programme 2003-2008.

\section{References}

1. European Centre for Disease Prevention and Control / WHO Regional Office for Europe. HIV/AIDS Surveillance in Europe 2007. Stockholm: European Centre for Disease Prevention and Control; 2008. Available from: http://ecdc.europa.eu/ en/publications/Publications/0812 SUR_HIV_AIDS_surveillance_in_Europe.pdf

2. Likatavi ius G, Klavs I, Devaux I, Alix J, Nardone A. An increase in newly diagnosed HIV cases reported among men who have sex with men in Europe, 2000-6: implications for a European public health strategy. Sex Transm Inf. 2008;84(6):499-505

3. Joint United Nations Programme on HIV/AIDS (UNAIDS) and World Health Organization (WHO). Monitoring the Declaration of Commitment on HIV/AIDS: guidelines on construction of core indicators: 2010 reporting. Geneva: UNAIDS 2009. Available from: http://www.unaids.org

4. Colfax G, Coates TJ, Husnik MJ, Huang Y, Buchbinder S, Koblin B, et al Longitudinal patterns of methamphetamine, popper (amylnitrite), and cocaine use and high-risk sexual behavior among a cohort of San Francisco men who have sex with men. J Urban Health. 2005;82(1 Suppl 1):i62-70.

5. Mansergh G, Flores S, Koblin B, Hudson S, McKirnan D, Colfax GN, et al. Alcohol and drug use in the context of anal sex and other factors associated with sexually transmitted infections: results from a multi-city study of high-risk men who have sex with men in the USA. Sex Transm Infect. 2008;84(6):509-11

6. Folch C, Esteve A, Zaragoza K, Muñoz R, Casabona J. Correlates of intensive alcohol and drug use in men who have sex with men in Catalonia, Spain. Eur J Public Health. 2009 Jun 29.

7. Drumright LN, Strathdee SA, Little SJ, Araneta MR, Slymen DJ, Malcarne VL, et al. Unprotected anal intercourse and substance use before and after HIV diagnosis among recently HIV-Infected men who have sex with men. Sex Transm Dis. 2007:34(6):401-407

8. Bolding G, Hart G, Sherr L, Elford J. Use of crystal methamphetamine among gay men in London. Addiction. 2006;101(11):1622-30

9. Cowan SA, Haff J. HIV and risk behaviour among men who have sex with men in Denmark--the 2006 Sex Life Survey. Euro Surveill. 2008;13(48). pij=19050. Available from: http://www.eurosurveillance.org/ViewArticle. aspx?ArticleId $=19050$

10. Schwarcz S, Scheer S, McFarland W, Katz M, Valleroy L, Chen S, et al. Prevalence of HIV infection and predictors of high-transmission sexual risk behaviors among men who have sex with men. Am J Public Health. 2007;97(6):1067-75

11. Koblin BA, Husnik MJ, Colfax G, Huang Y, Madison M, Mayer K, et al.Risk factors for HIV infection among men who have sex with men. AIDS.2006;20(5):731-9

12. Joint United Nations Programme on HIV/AIDS (UNAIDS) and World Health Organization (WHO). Initiating second generation HIV surveillance systems: practical guidelines. Available from: http://www.who.int/hiv/pub/surveillance/ guidelines/en/index.html 
13. Joint United Nations Programme on HIV/AIDS (UNAIDS) and World Health Organization (WHO). The pre-surveillance assessment. Guidelines for planning serosurveillance of HIV, prevalence of sexually transmitted infections and behavioural components of second generation surveillance of HIV. Available from: http://www.who.int/hiv/pub/surveillance/sti/en/index.html

14. Joint United Nations Programme on HIV/AIDS (UNAIDS). Monitoring the Declaration of Commitment on HIVAIDS - guidelines on construction of core indicators - 2008 Reporting UNGASS. Available from: http://www.unaids.org

15. Williamson LM, Hart GJ. HIV prevalence and undiagnosed infection among a community sample of gay men in Scotland. J Acquir Immune Defic Syndr. 2007; $45(2): 224-30$

16. Nokes DJ, Enquselassie F, Vyse A, Nigatu W, Cutts FT, Brown DW. An evaluation of oral-fluid collection devices for the determination of rubella antibody status in a rural Ethiopian community.Trans R Soc Trop Med Hyg. 1998;92(6):679-85

17. Ramsay M, Brugha R, Brown D. Surveillance of measles in England and Wales: implications of a national saliva testing programme. Bull World Health Organ. 1997;75(6):515-21.

18. Stueve A, O'Donnell LN, Duran R, San Doval A, Blome J. Time-space sampling in minority communities: results with young Latino men who have sex with men. Am J Public Health. 2001;91(6):922-6

19. MacKellar DA, Gallagher KM, Finlayson T, Sanchez T, Lansky A, Sullivan PS. Surveillance of HIV risk and prevention behaviors of men who have sex with men: a national application of venue-based, time-space sampling. Public Health Rep 2007;122 Suppl 1:39-47

20. Gallagher KM, Finlayson T, Sanchez T, Lansky A, Sullivan PS. Surveillance of HIV risk and prevention behaviors of men who have sex with men-a national application of venue-based, time-space sampling. Public Health Rep. 2007;122 Suppl 1:39-47

21. Muhib FB, Lin LS, Stueve A, Miller RL, Ford WL, Johnson WD, et al. A venue-based method for sampling hard-to-reach populations. Public Health Rep. 2001;116 Suppl 1:216-22

22. Folch C, Casabona J, Munoz R, Zaragoza K. [Trends in the prevalence of HIV infection and risk behaviors in homo- and bisexual men]. Gac. Sanit. 2005;19(4):294-301. Spanish.

23. Genscreen HIV-1|2 Assay Version 2 Bio-Rad Laboratories, Inc.1000 Alfred Nobel Drive Hercules CA 94547 United States 5107247000, http://www.bio-rad. com

24. Lambert NL, Fisher M, Imrie J, Watson R, Mercer CH, Parry JV, et al. Community based syphilis screening: feasibility, acceptability, and effectiveness in case finding. Sex Transm Infect. 2005;81(3):213-216

25. Pérez K, Rodes A, Casabona J. Monitoring HIV prevalence and behaviour of men who have sex with men in Barcelona, Spain. Euro Surveill. 2002;7(2):pii=345. Available from: http://www.eurosurveillance.org/ViewArticle. aspx?ArticleId $=345$

26. Marcus U, Voss L, Kollan C, Hamouda. HIV incidence increasing in MSM in Germany: factors influencing infection dynamics. Euro Surveill. 2006;11(9):pii=645. Available from: http://www.eurosurveillance.org/ ViewArticle.aspx?ArticleId $=645$

27. Davidovich U, de Wit JB, Stroebe W. Assessing sexual risk behaviour of young gay men in primary relationships: the incorporation of negotiated safety and negotiated safety compliance. AIDS. 2000;14(6)701-6

28. Centre for Sexually Transmitted Infection and AIDS Epidemiological Studies of Catalonia (CEEISCAT). Integrated AIDS/HIV/STI Surveillance System of Catalonia (SIVES): biennial epidemiological report [Internet]. Barcelona: Generalitat de Catalunya, Departament de Salut; 2008 - Technical document 19. Available from: http://www.ceescat.org/Index_Ing.htm

29. Klavs I, Poljak M. Unlinked anonymous monitoring of human immunodeficiency virus prevalence in high- and low-risk groups in Slovenia, 1993-2002. Croatian Med J. 2003:44(5):545-9

30. Staneková D, Habeková M, Wimmerová S, Gramblickova I. HIV infection and sexual behaviour among homosexuals and bisexual men in Bratislava. Cent Eur J Public Health. 2000;8(3):172-5 